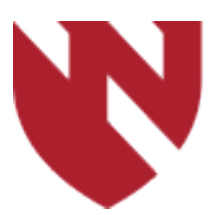

September 2020

\title{
Association of Agricultural, Occupational, and Military Inhalants With Autoantibodies and Disease Sevrity in U.S. Veterans with Rheumatioid Arthritis
}

\author{
Ariadne Ebel \\ University of Nebraska Medical Center \\ Gabrielle Lutt \\ University of Nebraska Medical Center \\ Jill A. Poole \\ University of Nebraska Medical Center \\ Geoffrey M. Thiele \\ University of Nebraska Medical Center \\ Joshua F. Baker \\ Philadelphia VA \& University of Pennsylvania
}

Tell us how you used this information in this short survey.

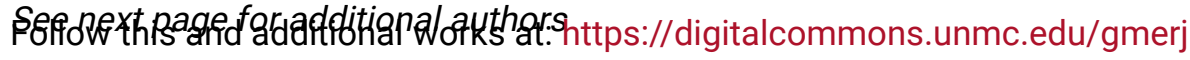

Part of the Higher Education Commons, and the Medicine and Health Sciences Commons

\section{Recommended Citation}

Ebel, A., Lutt, G., Poole, J. A., Thiele, G. M., Baker, J. F., Cannon, G. W., Gaffo, A., Kerr, G. S., Reimold, A., Schwab, P., Singh, N., Richards, S., Ascherman, D. P., Mikuls, T. R., , England, B. R. Association of Agricultural, Occupational, and Military Inhalants With Autoantibodies and Disease Sevrity in U.S. Veterans with Rheumatioid Arthritis. Graduate Medical Education Research Journal. 2020 Sep 29; 2(1). https://digitalcommons.unmc.edu/gmerj/vol2/iss1/48 


\section{Association of Agricultural, Occupational, and Military Inhalants With}

Autoantibodies and Disease Sevrity in U.S. Veterans with Rheumatioid Arthritis

\section{Creative Commons License}

\section{cc) (i) $\Theta \Theta$}

This work is licensed under a Creative Commons Attribution-Noncommercial-No Derivative Works 4.0 License.

\section{Authors}

Ariadne Ebel, Gabrielle Lutt, Jill A. Poole, Geoffrey M. Thiele, Joshua F. Baker, Grant W. Cannon, Angelo Gaffo, Gail S. Kerr, Andreas Reimold, Pascale Schwab, Namrata Singh, Steuart Richards, Dana P. Ascherman, Ted R. Mikuls, and Bryant R. England 


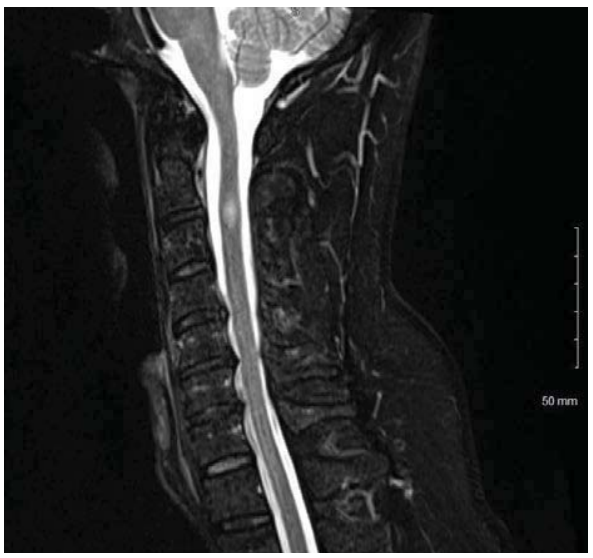

onset of symptoms, we cannot infer a causal relationship between the two. While CESIs are a safe intervention, including in patients with multiple sclerosis, physicians must always be vigilant for red flag symptoms including fever, chills, worsening pain, loss of bladder or bowel function, weakness, and new onset of sensory deficits. Timely workup decreases the time between symptom onset and diagnosis which may reduce the risk of permanent neurologic deficits.

https://doi.org/10.32873/unmc.dc.gmerj.2.1.044

Figure 1. MRI of cervical spine 48 hours after cervical epidural steroid injection (C6-7 level) demonstrating a new, enhancing spinal cord lesion at $\mathrm{C} 2$ and $\mathrm{C} 3$ consistent with active demyelination.

\section{Advance Care Planning: A Quality Improvement Project to Increase Patient Access and Provider Reimbursement \\ Michael Dobson', Richard Fruehling ${ }^{1}$ \\ ${ }^{1}$ University of Nebraska Medical Center, Department of Family Medicine}

Mentor: Richard Fruehling

Program: Family Medicine - Rural Medicine

Type: Original Research

Background: Advanced care planning (ACP) is an important intervention that improves end of life care. In 2016, CMS introduced new billing codes to reward providers already performing $\mathrm{ACP}$, and to incentivize those who were not. In 2016 - the year the codes were introduced - national data indicated only $1.9 \%$ of Medicare beneficiaries over 65 had an ACP claim during any visit. In 2017 this increased to $2.2 \%$. Among a group practice of fourteen providers in Grand Island, Nebraska, no claims had ever been made before October of 2019 .

Methods: A short, one hour information session provided guidance on the new ACP codes as well as evidence-based strategies for having these often difficult conversations. Claims made over the next two months were measured, along with corresponding data about setting, and patient characteristics.

Results: In just two months, over one hundred claims were made in this group practice, mostly during Medicare wellness visits but also across many settings including nursing homes and inpatient admissions. Providers reported that after the information session they were better equipped and more willing to provide ACP and properly bill for the service.

Conclusion: ACP was already performed by these providers before the information session but after the session they were more willing to engage their patients in ACP and captured a significant amount of revenue. We believe this information session could be easily replicated to expand ACP and improve the dismal national reimbursement.

https://doi.org/10.32873/unmc.dc.gmerj.2.1.046

\section{Association of Agricultural, Occupational and Military Inhalants With Autoantibodies and Disease Severity in U.S. Veterans with Rheumatoid Arthritis}

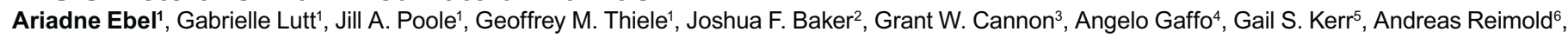
Pascale Schwab ${ }^{7}$, Namrata Singh ${ }^{8}$, Steuart Richards ${ }^{9}$, Dana P. Ascherman ${ }^{9}$, Ted R. Mikuls ${ }^{1}$, Bryant R. England ${ }^{1}$

${ }^{1}$ University of Nebraska Medical Center, Department of Internal Medicine, Division of Rheumatology

${ }^{2}$ Philadelphia VA \& University of Pennsylvania, Philadelphia, PA

${ }^{3}$ Salt Lake City VA \& University of Utah, Salt Lake City, UT

${ }^{4}$ Birmingham VA \& University of Alabama at Birmingham, Birmingham, $\mathrm{AL}$

${ }^{5}$ Washington DC VA, Georgetown, \& Howard University, Washington DC

${ }^{6}$ Dallas VA \& University of Texas Southwestern, Dallas, TX

${ }^{7}$ Portland VA \& Oregon Health Science University, Portland, OR

${ }^{8}$ Iowa City VA \& University of lowa, lowa City, IA

${ }^{9}$ Pittsburg VA \& University of Pittsburgh

Mentor: Bryant R. England

Program: Internal Medicine, Division of Rheumatology

Type: Original Research
Background: Cigarette smoke is a known inhalant exposure that contributes substantially to the risk and severity of rheumatoid arthritis (RA). Less is known about the link between other inhalant exposures and RA. The aim of this study was to determine the association between occupational, agricultural, and military inhalant exposures with RA-related factors.

Methods: Participants at nine sites in the Veterans Affairs Rheumatoid Arthritis 
(VARA) Registry were mailed surveys assessing occupational, agricultural, and military inhalant exposures. Demographics, disease activity, functional status, and extraarticular features were obtained from the VARA registry database. HLA-DRB1 shared epitope (SE) status, anti-CCP antibodies, and rheumatoid factor (RF) were measured using banked serum from VARA enrollment. Cross sectional associations between inhalant exposures and RA-related factors were assessed using multivariable linear and logistic regression models adjusting for age, sex, race, and tobacco use and stratified by SE status.

Results: In total, 797 of 1566 participants returned questionnaires (50.9\%). Responders were older, white, males, less frequent smokers, with better disease activity and functional status. Multiple inhalant exposures were associated with lung disease but not RF or disease activity. Burn pit exposure was significantly associated with anti-CCP positivity (OR 1.66, 95\% CI 1.02-2.69). In models examining combined burn pit exposure and SE status, those with both risk factors demonstrated a substantially higher risk of anti-CCP positivity (OR 5.69, 95\% CI 2.73-11.87) (Figure 1)

Conclusion: Burn pit exposure was associated with anti-CCP antibodies, particularly among those positive for HLADRB1 SE. These findings are consistent with emerging evidence that various inhalant

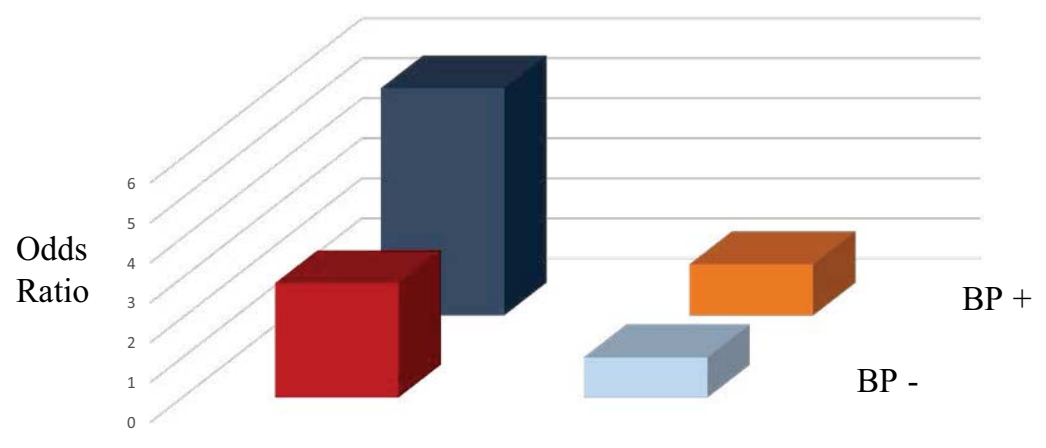

\begin{tabular}{|l|c|l|}
\hline \multicolumn{1}{|c}{ SE +} & SE - & $\begin{array}{c}\text { Odds ratio \& 95\% CI } \\
\text { for anti-CCP + }\end{array}$ \\
\hline Neither SE or Burn Pit & Anti-CCP + / Total & Referent \\
\hline SE Alone & $110 / 187(58.8)$ & $2.86(1.92-4.26)$ \\
\hline Burn Pit Alone & $21 / 32(65.6)$ & $1.28(0.58-2.86)$ \\
\hline SE \& Burn Pit & $83 / 93(89.3)$ & $5.69(2.73-11.87)$ \\
\hline \multicolumn{2}{|l}{ Odds ratios were adjusted for age, sex, race, and tobacco use } \\
\hline
\end{tabular}

Figure 1. Gene-environment interaction of shared epitope (SE) and burn pit (BP) exposure.

exposures influence autoantibody expression and RA risk.

Results: From analyses stratified by SE status demonstrated a gene-environment interaction between SE alleles and military burn pit exposure on anti-CCP antibodies. When stratified by SE status, the association between military burn pits and anti-CCP positivity was limited to those with the SE.
The combination of burn pit exposure and the SE allele had a stronger association with anti-CCP positivity than either risk factor in isolation.

Abbreviations: anti-CCP; cyclic-citrullinated peptide antibody; BP, burn pit; CI, confidence interval; SE, shared epitope.

https://doi.org/10.32873/unmc.dc.gmerj.2.1.047

\section{Adding Up to a Real Crisis}

Steven Embry ${ }^{1}$, Jacqueline Yurgil ${ }^{1}$

${ }^{1}$ University of Nebraska Medical Center, Department of Family Medicine

Mentor: Jacqueline Yurgil

Program: Family Medicine

Type: Case Report

Background: Addison's disease is an autoimmune destruction of the adrenals resulting in reduced glucocorticoid and mineralocorticoid production. During times of physiologic stress, insufficient replacement of these steroid hormones may precipitate a life-threatening adrenal crisis characterized by circulatory collapse and electrolyte abnormalities. Unfortunately, no formal guidelines currently exist for steroid adjustments in athletes.

\section{Methods: Physical Exam}

Results: A 14 y/o M with Addison's disease presented for a preparticipation physical evaluation (PPE) for football. Patient managed with BID Hydrocortisone and daily Fludrocortisone. Denied symptoms of adrenal insufficiency including salt cravings, fatigability, muscle aches, orthostasis or polyuria. No prior crises. Patient had never stress-dosed his steroids for athletics. Family desired strategies to minimize risks of participation. Physical exam, vitals, and CMP were normal aside from diffuse skin hyperpigmentation. It was determined he was on an adequate steroid regimen, an action plan for crisis was finalized, and he was educated on preventative strategies. At follow up, patient had completed football season without complications.

Conclusion: Addisonian athletes should be co-managed with Endocrinology and on a physiologic steroid regimen with TID or BID Hydrocortisone and daily Fludrocortisone. Prophylactic stress-doses of Hydrocortisone may be considered prior to athletic activity, especially if experiencing any symptoms of adrenal insufficiency, and should be strongly considered after injury. Early signs of crisis are often nonspecific, such as vomiting, abdominal pain, dizziness and muscle weakness. Immediate access to Solu-Medrol and emergency transportation may be lifesaving in the event of a crisis. To mitigate risk, athletes should also be coached on the importance of adequate hydration and electrolyte replacement.

https://doi.org/10.32873/unmc.dc.gmerj.2.1.048 